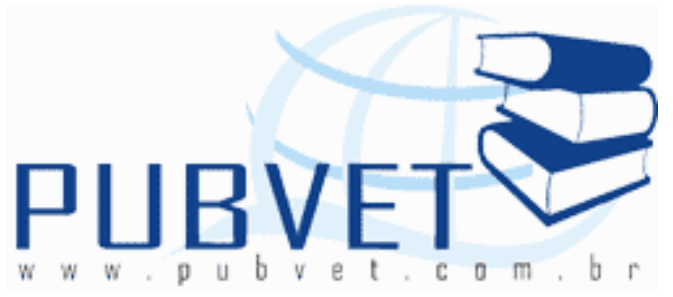

PUBVET, Publicações em Medicina Veterinária e Zootecnia.

\title{
Análise da utilização das ferramentas de gestão pelos pequenos produtores de leite no Município de Douradoquara no ano de 2012
}

\section{Cláudia Matildes Leite ${ }^{1}$ e Cláudio Costa ${ }^{2}$}

1 Graduando do Curso de Administração - FUCAMP - Fundação Carmelitana Mário Palmério.

2 Professor titular da FUCAMP - Monte Carmelo-MG.

\section{Resumo}

No atual cenário de produção de leite é visível a importância de se administrar bem a propriedade, tendo assim uma posição de empresário rural, que proporciona ao produtor maneiras de analisar e tomar melhores decisões em seu negócio. Neste trabalho a pesquisa busca analisar a utilização das ferramentas de gestão por estes pequenos produtores de leite no município de Douradoquara no ano de 2012. A metodologia adotada foi uma pesquisa exploratória, levantando informações por meio de questionários, que foram aplicados aos produtores que se encaixam neste perfil. As tabelas 01 e 02 buscam analisar e caracterizar o produtor em relação a sua propriedade, suas perspectivas e o sistema de produção utilizadas nas mesmas, e nas demais tabelas 03 a 05 verifica-se a utilização das ferramentas de gestão e quais eram. Os resultados obtidos foram analisados, constatando-se que na área de recursos humanos, anotações financeiras, controle, planejamento e qualificação foram encontradas poucas ações de gestão nas atividades. Portanto, diante dos estudos e resultados obtidos, conclui-se que é 
LEITE, C.M. e COSTA, C. Análise da utilização das ferramentas de gestão pelos pequenos produtores de leite no Município de Douradoquara no ano de 2012. PUBVET, Londrina, V. 7, N. 13, Ed. 236, Art. 1555, Julho, 2013.

considerada baixa a utilização das ferramentas de gestão pelos pequenos produtores de leite do município de Douradoquara-MG no ano de 2012.

Palavras Chave: Agronegócio; Agricultura Familiar; Controle rural.

\title{
Analysis of management tools use for small milk producers from the town of douradoquara in the year of 2012
}

\begin{abstract}
In today scenery of milk production is visible the importance of managing your property well, so having a position of rural entrepreneurs, the producer who provides ways to analyze and make better decisions in your business. In this work, the research seeks to analyze the use of management tools for small producers of Milk in the municipality of Douradoquara in 2012. Wich it was the methodology adopted by an exploratory research, raising information through questionnaires, wich were applied to producers Who fit in this profile. Table 01 and 02 seeks to analyse and characterize the producer in relation to their property, their prospects and the production system used in it, and in the other questions sought to ascertain whether there was the use of management tools and what they were. Following the results were analyzed, noting that in the area of human resources, financial notes, control, planning and qualification found few stoks of management activities. So before the studies and results indicate that it is considered low the utilization management tools for small Milk producers in the municipality of Douradoquara-MG in 2012.
\end{abstract}

Keywords: Agribusiness; Family Farming; Rural Control.

\section{Introdução}

O cenário atual do agronegócio está passando por várias mudanças, devido ao aumento de preços de insumos, o custo de produção está exageradamente elevado, esse fenômeno é ainda mais preocupante no mercado leiteiro, por isso a exigência por um maior controle na propriedade é 
LEITE, C.M. e COSTA, C. Análise da utilização das ferramentas de gestão pelos pequenos produtores de leite no Município de Douradoquara no ano de 2012. PUBVET, Londrina, V. 7, N. 13, Ed. 236, Art. 1555, Julho, 2013.

ainda maior, pois assim o produtor sabe em qual situação se encontra seu negócio.

A agricultura familiar, atualmente, é composta por uma considerável soma de pequenos produtores rurais com baixos níveis de escolaridade, no ramo da produção de leite. Possui um papel fundamental para a economia e para a manutenção da população no campo e na cidade, pois é através da produção de leite e variáveis alimentos, que a família consegue suprir suas necessidades e investir em sua propriedade (NAPOLEÃO, 2010).

A produção de leite representa uma das principais atividades econômicas, com geração de emprego e de renda. Minas Gerais, por sua tradição, clima e topografia é o maior Estado produtor de leite e queijos do País é responsável por mais da metade da produção nacional. Atualmente há uma concentração da produção leiteira em estabelecimentos pequenos, contendo na maioria das pequenas propriedades mão-de-obra familiar (LIMA, 2011).

Os desafios da atividade leiteira no Brasil vêm aumentando e acumulando nos últimos tempos, segundo Ruas (2010) a sobrevivência dos produtores rurais neste cenário competitivo depende de questões relacionadas ao gerenciamento da propriedade. A gestão familiar nada mais é que o processo de administrar seu negócio, ou seja, planejar, organizar, dirigir e controlar (MAXIMIANO, 2000).

Várias características podem afetar a gestão da propriedade rural, como por exemplo, a inovação no processo de administração ou a adoção de uma nova tecnologia para produção. Os produtos agrícolas brasileiros estão passando por vários processos de mudanças estruturais, necessitando cada vez mais de novas tecnologias. Uma das características observadas relacionadas ao mercado consumidor são as exigências por produtos seguros, ou seja, que obedecam aos padrões rígidos de qualidade. Para a implantação satisfatória desses padrões nas propriedades rurais, se faz necessário que o produtor rural adote sistemas de informação e modernos métodos de gestão empresarial (ZUIN; RAMOS, 2006). 
Portanto, uma ótima gestão da propriedade rural poderá proporcionar ao produtor informações de gerenciamento que são capazes de auxiliar, identificar e melhorar seu manejo, contribuindo para a maximização de seus lucros. Assim, este trabalho teve como objetivo analisar a utilização das ferramentas de gestão pelos pequenos produtores de leite em DouradoquaraMG no ano de 2012.

\section{2 - A Importância da Agricultura familiar}

Com a ação do homem sobre o processo produtivo, pode-se definir que a agricultura familiar descreve a arte de cultivar a terra, com o objetivo de atender suas necessidades e satisfações. O processo produtivo pode ser considerado como um conjunto de eventos, processos e ações que por sua vez transformam os produtos vegetais e animais para a utilização do homem. É também um sistema de preparar a terra para plantar, tratar e colher, como a finalidade de obter alimentos para a sobrevivência do homem e do animal (SANTOS et al, 2008).

A agricultura familiar considera-se bastante complexa, inclui tanto as famílias que vivem e exploram minifúndios, como produtores inseridos no moderno agronegócio e que buscam gerar rendas maiores que as definidas. Os agricultores se diferenciam conforme a disponibilidade de recursos, capacidade de geração de renda, potencialidade, capacitação e aprendizado (BATALHA, SOUZA, 2005).

A agricultura familiar não significa pobreza, tudo varia conforme a organização e o controle que são geridos pela família. Por meio de vários aspectos importantes como a produção, o trabalho, a gerência, as decisões e o capital é que a família consegue retirar seu sustento e obter seus lucros (RIBEIRO, 2011). As atividades, de acordo com Ribeiro, Oliveira e Ferreira (2000), exercidas pelo grupo familiar na empresa rural são aquelas necessárias para a produção e comercialização do produto, dentro e fora da 
LEITE, C.M. e COSTA, C. Análise da utilização das ferramentas de gestão pelos pequenos produtores de leite no Município de Douradoquara no ano de 2012. PUBVET, Londrina, V. 7, N. 13, Ed. 236, Art. 1555, Julho, 2013.

propriedade, antes, durante e depois da produção. Portanto, a família deve enxergar mais que o interior da propriedade e mais que a produção em si.

O tema da agricultura familiar surgiu no Brasil em meados da década de 1990. Porém, Fontanétti e Santos (2010) consideram que a sua afirmação no cenário social e político brasileiro, está relacionada com a legitimação que o Estado the emprestou ao criar, em 1996, o Programa Nacional de Fortalecimento da Agricultura Familiar (Pronaf). Este projeto tinha como objetivo prover crédito agrícola e apoio institucional às categorias de pequenos produtores rurais, com essas mudanças essa categoria poderia se manter na atividade e aumentar a produção.

Por causa das novas demandas no mercado atual o agricultor tem diminuído o número de atividades em seu estabelecimento rural e segundo Crepaldi (2005) estão dedicando-se apenas uma ou duas destas, especializando e inovando para melhorar a qualidade de seus produtos, podendo sobressair mais no mercado e receber um melhor preço.

A agricultura familiar diante dos outros modelos de agricultura está tendo pouco poder de barganha, ou seja, a precariedade da infraestrutura de produção e comercialização e a falta de financiamento adequado tem levado à saída de agricultores para a cidade. Portanto, é preciso fortalecer esta agricultura, através de variáveis que envolvam maior poder de barganha com fornecedores e distribuidores, maior cooperação com outros produtores, maior poder de convencimento em agências financiadoras e melhor gerência sobre a forma de produção (MENDONÇA; SANTOS, 2010).

A agricultura no Brasil, conforme Santos, Marion e Cegaste (2008) possui um cenário de realidades opostas onde a maior renda e área está concentrada na mão da minoria. Para ocorrer o fortalecimento do agronegócio nacional, conforme Fontanétti e Santos (2010) vai depender da valorização do potencial econômico da agropecuária familiar, além do amplo reconhecimento da sua contribuição para segurança alimentar local e regional e do seu papel social e cultural dentro da sociedade. 
LEITE, C.M. e COSTA, C. Análise da utilização das ferramentas de gestão pelos pequenos produtores de leite no Município de Douradoquara no ano de 2012. PUBVET, Londrina, V. 7, N. 13, Ed. 236, Art. 1555, Julho, 2013.

\section{3 - A Importância da Produção de leite}

No mercado atual, um dos principais desafios da humanidade é a produção de alimentos para suprir a demanda da população, que nos últimos anos, só vem aumentando. Os animais ruminantes têm papel importante de transformar produtos que não são utilizados pelo homem, como o capim, em alimentos que contêm proteína de alta qualidade, vitaminas, minerais e energia. As vacas leiteiras são produtoras do leite, este alimento é descrito como o mais perfeito da natureza (SILVA, SANCHES, 2010).

A competitividade do sistema de produção de leite não envolve somente produtividade, conforme Ruas et al. (2010) é necessário que haja uma matriz diferenciada que se adapte ao sistema e que a exploração seja feita à base de pastagens, produzindo leite de qualidade e a baixo custo, diminuindo a ociosidade.

A partir dos anos 90 segundo Pinto (2011) começou a ser exigido um aumento no padrão de qualidade na obtenção do leite e derivados no Brasil, com o objetivo de ser nivelado aos padrões do Mercosul e da indústria de lácteos, além de atender as exigências e demanda dos consumidores por produtos de qualidade e custos competitivos. A mudança de maior impacto foi a obrigação de refrigeração do leite na fonte de produção e no seu transporte a granel pelos caminhões tanques.

A refrigeração do leite cru na fonte de produção beneficia os produtores, por reduzir perdas de acidez, preservando o leite evitando riscos de doenças, além de que o leite cru resfriado agrega mais valor econômico, comparado com o leite cru que não é resfriado. Podendo receber o leite com o preço melhor quando a indústria paga por qualidade nos indicadores como contagem de células somáticas (CCS), contagem total de bactérias e teor de proteínas e gorduras (FONSECA, 2011).

A produção de leite no Brasil baseia-se em vacas mestiças, que constituem cerca de $70 \%$ do rebanho, com produção média de leite de apenas 1.200 litros por lactação / ano. Buscando um rebanho com vacas mais 
mestiças que possa equilibrar tanto genes para a produção de leite quanto gene para rusticidade e adaptação a condições tropicais (RUAS et al, 2010).

No estado de Minas Gerais, a base de alimentação do rebanho, segundo Oliveira, Pires e Leite (2010) é o pasto, sendo este um fator que contribui para diminuir o custo de produção. De acordo com essas informações, a estabilização do leite no decorrer do ano dificilmente vai acontecer, uma vez que, dessa forma estabelecida, motivaria o produtor a concentrar sua produção no período das chuvas, pois é neste período que se possui maior quantidade de pasto, obtendo assim um menor custo de produção.

As diversas informações e transformações que vêm ocorrendo têm contribuído para que os produtores de leite reflitam sobre a necessidade de administrarem bem a atividade, tornando-se mais eficientes e, consequentemente mais competitivos. Buscando utilizar instrumentos de apoio para tomadas de decisões seguras e corretas (LOPES et al., 2004).

\section{4 - Ferramentas utilizadas na gestão das propriedades rurais}

O proprietário rural deve saber administrar a atividade do seu negócio, dirigindo e controlando a organização por meio de técnicas e ferramentas de gestão, para alcançar os objetivos traçados com responsabilidade social e ambiental. O principal papel do Administrador Rural conforme Santos, Marion e Segatti (2009) é saber fazer planejamento, controlar as informações e dados, decidir os planos e avaliar se os resultados estão alcançando os objetivos, visando a permanência da motivação na atividade.

O gestor dever estar por dentro das facetas do negócio, pois o aumento do lucro e dos ganhos está interligado com as tomadas de decisões, a qual depende da capacidade gerencial do produtor, mas é preciso reconhecer que a falta de dado é geralmente a razão dos fracassos das decisões. Para que isso não ocorra é necessário que se identifique os objetivos, a situação atual, onde estão os entraves e como superá-los. Para obter esses dados devem-se fazer 
LEITE, C.M. e COSTA, C. Análise da utilização das ferramentas de gestão pelos pequenos produtores de leite no Município de Douradoquara no ano de 2012. PUBVET, Londrina, V. 7, N. 13, Ed. 236, Art. 1555, Julho, 2013.

anotações, pois assim adquirindo informações que irão auxiliar na gestão (COLBEK, 2011).

Começa agora a ser percebida a importância da administração em ser empregada na maioria das propriedades produtoras de leite e em outros empreendimentos do agronegócio. Além de ser essencial que ela esteja presente na propriedade nos níveis estratégico (planejamento), tático (gerencial) e operacional (prática) tendo assim eficiência na organização (CHIAVENATO; SAPIRO, 2003).

Frente a várias mudanças no mercado atual, constata-se que na maioria das organizações o grande diferencial pode ser considerado o capital humano, pois são eles que operacionalizam a organização, ou seja, responsáveis pelo sucesso ou fracasso. De modo que os resultados esperados sejam atingidos pelas empresas, vai surgir a necessidade de gerir eficientemente os colaboradores, necessitando também que as pessoas sejam capacitadas, qualificadas e conscientes da sua importância dentro do processo produtivo, e que suas funções, tarefas e metas sejam organizadas, controladas e geridas para garantir que o processo produtivo não seja um entrave à competitividade da empresa produtora de leite (CHIAVENATO, 2004).

Uma das ferramentas que podem ser utilizadas pelo pequeno produtor rural é o plano de negócio (planejamentos), ele representa uma oportunidade para que o produtor rural analise todas as facetas do seu negócio. O plano de negócio segundo Rosa (2009) é considerado como um instrumento básico de planejamento operacional que subsidia o processo da tomada de decisão, descrevendo os objetivos de seu negócio e os passos necessários para que esses objetivos sejam alcançados.

Um gestor deve saber qual é seu custo de produção, pois o seu negócio vai progredir influenciado pelo departamento financeiro. Para não haver fracassos pode ser utilizado na administração da propriedade o custo de produção, que segundo Gomes (2006) é justamente para indicar se o negócio tem possibilidade de sobreviver no mercado, com o resultado do cálculo do custo de produção o produtor tem como saber analisando-o com a renda se 
está tendo lucro/prejuízo. Com esses dados em mãos é mais fácil o produtor conseguir diminuir seu custo de produção, tanto os fixos como as variáveis, e quanto menor é o custo maior vai ser a margem de lucro.

Para conseguir ter esse controle o produtor não precisa ter conhecimento de contabilidade nem lançar os dados no computador para obter o resultado, de acordo com Gonçalves (2007), basta anotar todas as despesas e gastos com a produção de leite em uma caderneta, controlando o fluxo de caixa que é a entrada e saída do dinheiro, ou seja, receita e despesa, obtendo assim informações para orientar nas tomadas de decisões.

O produtor deve administrar o negócio de forma eficaz e eficiente, utilizando da gestão (técnicas e ferramentas), de tecnologia e planejamento além de estar atento a variações de preços dos insumos e de seu produto (leite) no mercado. Buscando evitar desperdícios, reduzindo os custos e em contrapartida maximizando o lucro (CAMPOS; PIACENTI, 2007).

Há várias técnicas e ferramentas utilizadas na gestão da produção que não precisam de investimentos imediatos, pois o mais importante é o produtor ter interesse, dedicação e informação. Com essas atitudes o produtor terá mais controle sobre o manejo do rebanho e também na administração geral da produção, condicionando assim uma maior eficiência no sistema de produção (GONÇALVES, 2007).

Atualmente, exige-se que o produtor rural tenha uma ótima gestão dos recursos utilizados no meio ambiente. Consequentemente, aumenta a responsabilidade referente ao destino correto dos resíduos gerados pela propriedade. De acordo com esses fatores os produtores devem utilizar a terra e os outros recursos naturais de maneira racional, ou seja, explorar o máximo que a propriedade pode oferecer, de modo a provocar o mínimo de impacto possível (GONÇALVES; COSTA, 2002) 
LEITE, C.M. e COSTA, C. Análise da utilização das ferramentas de gestão pelos pequenos produtores de leite no Município de Douradoquara no ano de 2012. PUBVET, Londrina, V. 7, N. 13, Ed. 236, Art. 1555, Julho, 2013.

\section{5 - Metodologia}

O desenvolvimento deste trabalho deu-se primeiramente por meio de informações bibliográficas sobre a importância da agricultura familiar, a produção de leite e as ferramentas utilizadas na gestão das pequenas propriedades rurais. Sendo aplicados questionários para um levantamento específico da situação atual dos produtores, obtendo assim uma pesquisa exploratória utilizando o método quantitativo.

A pesquisa foi aplicada no município de Douradoquara / MG que está situado em uma latitude de $47,6^{\circ}$ e uma longitude de $18,43^{\circ}$, com uma população de 1.841 habitantes, entre eles 471 são produtores rurais, esta área contem $313 \mathrm{~km}^{2}$, possuindo um bioma de cerrado e mata atlântica propício para a produção de leite e outras atividades, 471 (IBGE, 2012).

Os questionários aplicados foram baseados de acordo com o trabalho de Correa (2010), sendo adaptadas as questões que visam informar sobre o desempenho do produtor na atividade, que seguem em anexo, concluído com 20 questões, o perfil de levantamento dos produtores desta pesquisa foi concedida por um relatório fornecido pelo laticínio e a cooperativa localizados na região de Douradoquara -MG, que disponibilizou uma lista com os pequenos produtores de leite e suas referidas médias de produção, para posteriormente serem entrevistados pessoalmente.

As entrevistas foram feitas pessoalmente nas fazendas (casas) dos produtores e também durante a visita dos mesmos em estabelecimento comercial, eles foram orientados de que se tratava de um questionário para fins acadêmicos com o objetivo de analisar as características dos produtores, suas propriedades e também a utilização de ferramentas de gestão na atividade.

Identificado os percentuais de 01 a 20 questões de cada alternativa, geraram-se tabelas para apresentar as características desses produtores e diagnosticar se utilizavam ou não ferramentas de gestão nas diferentes áreas 
da propriedade. Ressalta-se que a aplicação dos questionários foi realizada entre os meses de setembro e outubro de 2012.

\section{6- Resultados e Discussão}

$\mathrm{Na}$ análise da tabela 01 observou-se que $48 \%$ dos entrevistados se encontram na atividade há mais de 20 anos. Entretanto 30\% continuam pelo motivo de ser uma atividade que emprega a família e que tem renda mensal. Conforme a análise percebe-se que um dos motivos é pelo custo ser alto, dificultando assim a saída e a falta de opções mais rentáveis. Em relação ao custo de saída da atividade, o trabalho entra em acordo com Gomes (2005), pois eles possuem um capital alto investido na propriedade.

As perspectivas para o próximo ano dos produtores que foram entrevistados é $38 \%$ querem continuar na mesma situação, em contrapartida $33 \%$ dos produtores têm pretensões de aumentar a produção. Devido ao cenário atual dessa atividade, apenas os produtores que buscarem informações e se adaptarem as novas demandas conseguirão se manter no ramo. Em relação às perspectivas e pretensões dos produtores serem baixa, Silveira e Pedrazzi (2002) relatam que nas atividades a utilização da mão de obra familiar, na maioria das vezes não é mecanizada ou precariamente mecanizada, levando-os a desmotivação pelo fato de ser difícil concorrer com produtores de alto nível.

Dos entrevistados a média de leite / dia com mais participantes é a de 181 a 230 It de leite, com $36 \%$ dos produtores. Os produtores se encontram nesta média há bastante tempo, portanto percebe-se que eles não buscam aumentar a produção, ou seja, continuam com o mesmo patamar de produção. 
Tabela 01 - Levantamento dos pequenos produtores de leite do município de Douradoquara-MG em 2012, quanto ao tempo de atuação na atividade, perspectivas para os próximos anos e incentivo para se produzir leite.

\begin{tabular}{lcc}
\hline Variáveis & $\begin{array}{c}\text { Quantidade } \\
\text { (n) }\end{array}$ & $\begin{array}{c}\text { Frequência } \\
(\mathbf{\%})\end{array}$ \\
\hline Tempo que atua na produção de leite & $\mathbf{1 2}$ & $\mathbf{1 5 \%}$ \\
1- De 0 à 3 anos & $\mathbf{6}$ & $\mathbf{8 \%}$ \\
2- De 4 à 8 anos & $\mathbf{1 1}$ & $\mathbf{1 4 \%}$ \\
3- Entre 9 à 14 anos & $\mathbf{1 3}$ & $\mathbf{1 6 \%}$ \\
4- Entre 15 à 20 anos & $\mathbf{3 8}$ & $\mathbf{4 8 \%}$ \\
5- Mais de 20 anos & $\mathbf{0}$ & $\mathbf{0 \%}$ \\
\hline $\begin{array}{l}\text { Motivo de se produzir leite } \\
\text { 1- Negócio lucrativo e mercado garantido }\end{array}$ & $\mathbf{2 4}$ & $\mathbf{3 0 \%}$ \\
2- Tem renda mensal e emprega a & & \\
família & $\mathbf{1 8}$ & $\mathbf{2 3 \%}$ \\
3- Combina com outras explorações & $\mathbf{3}$ & $\mathbf{4 \%}$ \\
4- Não sabe fazer outra coisa & $\mathbf{3 5}$ & $\mathbf{4 4 \%}$ \\
5- Já está dentro do mercado e acha & & \\
difícil sair &
\end{tabular}

\section{Perspectivas para o próximo ano}

1- Continuar como está

$30 \quad 38 \%$

2- Aumentar a produção

$26 \quad 33 \%$

3- Reduzir a produção

$16 \quad 20 \%$

4- Abandonar a atividade

8

$10 \%$

5- Outros

$\mathbf{0}$

$0 \%$

Média de produção de leite/dia

1- De a 80 litros

$6 \quad 8 \%$

2- De 81 a 130 litros

9

$11 \%$

3- De 131 a 180 litros

22

$28 \%$

4- De 181 a 230 litros

29

$36 \%$

5- De 231 a 280 litros

14 $18 \%$ 
$\mathrm{Na}$ análise das características da área produtora de leite da tabela 02, $38 \%$ dos entrevistados conseguem trabalhar nesta atividade em uma área de 13 a 19 hectares. Com essa mesma frequência de 38\% dos produtores utilizam acima de 27 hectares de área para a produção de leite. Os produtores buscam produzir em áreas menores contribuindo assim o bom desempenho da atividade e aproveitamento da terra destinada ao leite.

Tabela 02- Característica da área produtora de leite e do sistema de produção adotado no município de Douradoquara MG em 2012.

Variáveis

\section{Quantidade}

(n)

Tamanho da área destinada à produção de leite

1- Até 04 hectares

2- De 05 a 12 hectares

3- De 13 a 19 hectares

4- De 20 a 26 hectares

5- Acima de 27 hectares
Frequência

(\%)

$8 \%$

$11 \%$

$38 \%$

$6 \%$

$38 \%$

\section{Sistema de produção adotado na propriedade}

1- Pastagem contínua + concent./cana

2- Pastagem contínua + concent./silagem

3- Pastagem rotacionada + concent./cana

4- Pastagem rotacionada + concent./silagem

5- Pastag. Rotac. Irrigação + concent./cana

O sistema de produção adotado nas atividades é bastante complexo, podendo variar, na região $49 \%$ dos produtores entrevistados fazem utilização de pastagem contínua mais ração. Infelizmente apenas $6 \%$ adotam na propriedade pastagem com lotação rotacionada com irrigação mais concentrado/cana e $0 \%$ pastagem com lotação rotacionada com irrigação mais concentrado/silagem. Percebeu- se que quase $50 \%$ dos produtores utilizam de 
LEITE, C.M. e COSTA, C. Análise da utilização das ferramentas de gestão pelos pequenos produtores de leite no Município de Douradoquara no ano de 2012. PUBVET, Londrina, V. 7, N. 13, Ed. 236, Art. 1555, Julho, 2013.

tratos prontos evitando mão de obra para produzi-los, buscando alimentar seu gado com proteínas e vitaminas equilibradas, com o objetivo de aumentar sua produção de leite/animal, infelizmente possui baixo investimento em tecnologia de produção, por terem baixa concentração de pastagem rotacionada com irrigação.

Na tabela 03 verificou-se que $45 \%$ dos produtores têm transmissão de tarefas pela forma oral entre a família toda. Sendo que $0 \%$ não possui anotações para comunicar os controles da propriedade, constata-se que $26 \%$ dos entrevistados não possuem comunicação, pois trabalham sozinhos. Algumas pessoas que fazem parte da família podem não saber da situação atual que a propriedade se encontra, e até mesmo o próprio produtor que está desempenhando as funções, por não ter anotado os dados ocorridos, ficando sem informações da realidade do negócio.

$\mathrm{Na}$ área de controle da atividade leiteira 33\% fazem anotações em uma planilha, e $43 \%$ não fazem nenhum tipo de anotação. Os que anotam são com o objetivo de conferir no final do mês o leite vendido, portanto para avaliar o desempenho e progresso leiteiro por animal não é feito nenhum controle de reprodução, caso nenhuma ferramenta seja utilizada o produtor terá muitas dificuldades devido à falta de dados consistentes e reais, não conhecendo a realidade do empreendimento ele poderá cometer erros que serão dificilmente corrigidos.

Em contrapartida, o controle reprodutivo foi o mais praticado pelos produtores, $73 \%$ anotam em cadernos a data da prenhês e a programação do parto, e $28 \%$ não fazem anotações. Outros controles mais praticados na propriedade, de acordo com os entrevistados, são os da qualidade do leite e controle de pastagem contendo uma freqüência de $28 \%$. Os produtores necessitam ter o controle da prenhês para programar a data do parto, evitando assim problemas futuros de infecção, fraqueza, entre outros nos animais. Em relação à percentagem que busca qualidade do leite, percebe-se que um dos motivos da grande demanda é porque os produtores estão sendo exigidos 
LEITE, C.M. e COSTA, C. Análise da utilização das ferramentas de gestão pelos pequenos produtores de leite no Município de Douradoquara no ano de 2012. PUBVET, Londrina, V. 7, N. 13, Ed. 236, Art. 1555, Julho, 2013.

pelos laticínios para oferecerem qualidade no leite, para serem remunerados por isso e também garantir sua permanência.

Tabela 03- Processos de controles, planejamento, organização e comunicação nas pequenas propriedades do município de Douradoquara MG em 2012.

\begin{tabular}{|c|c|c|}
\hline Variáveis & Quantidade (n) & $\begin{array}{c}\text { Frequência } \\
(\%)\end{array}$ \\
\hline \multicolumn{3}{|l|}{ Comunicação e controle no trabalho. } \\
\hline 1- Oral entre a família toda & 36 & $45 \%$ \\
\hline 2- Oral, através do trabalho & 23 & $29 \%$ \\
\hline 3- Escrita, anotações em um quadro & $\mathbf{0}$ & $0 \%$ \\
\hline 4- Não há comunicação, pois trabalho só. & 21 & $26 \%$ \\
\hline \multicolumn{3}{|l|}{ Controle leiteiro } \\
\hline 1- Anota em um caderno & 20 & $25 \%$ \\
\hline 2- Anota em uma planilha de controle & 26 & $33 \%$ \\
\hline 3- Anota em um computador & $\mathbf{0}$ & $0 \%$ \\
\hline 4- Não anota & 34 & $43 \%$ \\
\hline \multicolumn{3}{|l|}{ Controle Reprodutivo } \\
\hline 1- Anota em um caderno & 58 & $73 \%$ \\
\hline 2- Anota em uma planilha de controle & $\mathbf{0}$ & $0 \%$ \\
\hline 3- Anota em um computador & $\mathbf{0}$ & $0 \%$ \\
\hline 4- Não anota & 22 & $28 \%$ \\
\hline \multicolumn{3}{|l|}{ Controles praticados na propriedade } \\
\hline 1- Controle de temperatura de tanque & 8 & $10 \%$ \\
\hline 2- Controle de qualidade de leite & 22 & $28 \%$ \\
\hline 3- Controle de descarte de leite & 18 & $23 \%$ \\
\hline 4- Controle de histórico dos animais & 10 & $13 \%$ \\
\hline 5- Controle de pastagens & 22 & $28 \%$ \\
\hline \multicolumn{3}{|l|}{ Como é feito o custo da produção de leite. } \\
\hline 1- Anota gastos no caderno ref. Prod. De leite & 33 & $41 \%$ \\
\hline 2- Utiliza uma planilha & 12 & $15 \%$ \\
\hline 3- Utiliza um computador & 0 & $0 \%$ \\
\hline 4- Não tem nenhum tipo anotação & 35 & $44 \%$ \\
\hline \multicolumn{3}{|l|}{ Principal uso da informação sobre o custo. } \\
\hline 1- Para questionar o laticínio sobre o leite rec. & 4 & $5 \%$ \\
\hline 2- Identificar a margem de lucro & 13 & $16 \%$ \\
\hline 3- Avaliar como está o desempenho da ativid. & 27 & $34 \%$ \\
\hline 4- Não sabe como calcular & 11 & $14 \%$ \\
\hline 5- Não tem tempo para calcular & 25 & $31 \%$ \\
\hline
\end{tabular}


LEITE, C.M. e COSTA, C. Análise da utilização das ferramentas de gestão pelos pequenos produtores de leite no Município de Douradoquara no ano de 2012. PUBVET, Londrina, V. 7, N. 13, Ed. 236, Art. 1555, Julho, 2013.

Em relação ao controle de custo da produção de leite $44 \%$ dos entrevistados não fazem nenhum tipo de anotação para saber qual é o seu custo, $31 \%$ dizem não ter tempo para calcular. O fato de não possuírem a relação do custo de sua produção pode levá-los ao desperdício, perdas, descapitalização entre outros fatores, é muito importante saber em qual nível se encontra a produção, para assim tomar decisões acertadas objetivando o aumento do lucro. O preço atual do leite se encontra inferior aos custos de produção, portanto é de grande importância o produtor identificar seus gastos, e para conseguir sobreviver no mercado, está implantando Sistemas de Produção de Leite a Pasto, ou seja, procurando diminuir seu custo (OLIVEIRA, PIRES; LEITE, 2010).

Em relação ao planejamento da atividade, conforme tabela 04, 80\% fazem mensal, apenas $10 \%$ fazem planejamento anual e $10 \%$ dos entrevistados não fazem nenhum tipo de planejamento. No período da seca $86 \%$ programam com antecedência o que utilizar de alimentação. Portanto alguns produtores pelo fato de não se programarem podem apresentar dificuldades financeiras, pois eles não têm definido o que querem em curto prazo, médio e longo prazo. Devido sua renda e movimentação ser mensal, acredita-se ser mais viável programar e planejar junto à situação financeira. Diante desses resultados os produtores não estão no caminho certo quando fazem planejamento apenas mensal, pois conforme Gomes (2008) o sucesso ou o fracasso da atividade é observado em médio prazo, portanto é necessário planejar ações mensais e anuais.

De acordo com as funções desempenhadas no dia-a-dia 55\% programam para realizar ordenha o restante das funções é de acordo com a necessidade. Portanto o desenvolvimento das funções e processos são feitos conforme a prioridade do momento.

Os resultados apresentados a respeito da qualificação foi que $63 \%$ acreditam estarem qualificados por trabalharem há bastante tempo na atividade e porque aprenderam muito com seus pais, devido a isso apenas $11 \%$ estão buscando participar de cursos e treinamento para se qualificarem. 
LEITE, C.M. e COSTA, C. Análise da utilização das ferramentas de gestão pelos pequenos produtores de leite no Município de Douradoquara no ano de 2012. PUBVET, Londrina, V. 7, N. 13, Ed. 236, Art. 1555, Julho, 2013.

Por acharem que não precisam participar de cursos e treinamentos, deixam passar oportunidades que seriam de vital importância em seus negócios, como por exemplo melhorar o manejo, controle, sistemas de produção entre outras áreas que sempre está passando por mudanças.

Tabela 04- Processos de planejamentos e qualificações adquiridos e praticados pelos pequenos produtores rurais de Douradoquara MG em 2012.

\section{Variáveis}

Quantidade Frequência

(n)

(\%)

\section{Como é feito o planejamento na propriedade}

1- Mensal

64

$80 \%$

2- Trimestral

0

$0 \%$

3- Semestral

0

$0 \%$

4- Anual

8

$10 \%$

5- Não faz planejamento

8

$10 \%$

Faz planejamento no período da seca.

1- Sim define se vai usar concent. silo ou ração

$86 \%$

2- Não, define no momento que há necessidade

\section{Planejamento para desempenhar as funções}

1- Tem horário para fazer todas as funções/dia

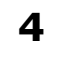

$5 \%$

2- Planj. para tirar o leite, as outras varia

$55 \%$

3- Planj. para tirar leite, tratar, medic. e varia

4- Não planj. pois é de acordo c/ a necessidade

5- Não por ter várias funções, não sabe definir

\section{Consideram que estão qualificados}

5

$6 \%$

1- Sim, estamos participando de treinamento

2- Sim, não estamos partic. de treinamento

9

15

3- Não, mas estamos partic. de treinamento

4- Não, pois não é oferecido treinamento

5- Sim, pois aprendemos com nossos pais
0

6

50
$11 \%$

$19 \%$

$0 \%$

$8 \%$

$63 \%$

Observou-se na tabela 05 que na busca por conhecimento, 34\% dizem buscar informações fora da porteira através de conversas com outros produtores, a menor percentagem apresentada é de $9 \%$, os quais buscam conhecimento por meio de revista, retratando assim que poucos produtores 
LEITE, C.M. e COSTA, C. Análise da utilização das ferramentas de gestão pelos pequenos produtores de leite no Município de Douradoquara no ano de 2012. PUBVET, Londrina, V. 7, N. 13, Ed. 236, Art. 1555, Julho, 2013.

são motivados para a leitura. Acredita-se que uma das ferramentas mais utilizadas para agregar informações é por meio de conversas com outros produtores e estabelecimentos agropecuários e laticínios, pois é o ambiente que o produtor mais frequenta, portanto mais fácil para se atualizar e informar.

Tabela 05- Buscas por processos que agregam conhecimentos, qualidade, conservação e higiene dentro da propriedade rural e fora dela no município de Douradoquara / Mg em 2012.

\section{Variaveis}

Quantidade Frequência

(n)

(\%)

\section{Buscam informações fora da porteira}

1- Através de conversas com outros produtores

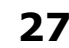

$34 \%$

2- Sim, através da televisão e o rádio

3- Sim, através das lojas de agronegócio

21

$26 \%$

4- Sim, através de revistas

7

$9 \%$

5- Não, consigo me informar fora da porteira

$\mathbf{0}$

$0 \%$

\section{Tem conhecimento da instrução normativa 62}

1- Sim

58

$73 \%$

2- Não

22

$\mathbf{2 8} \%$

\section{Quais são os procedimentos de rotina de higiene}

1- Limpeza e desinfecção da sala de ordenha

13

$16 \%$

2- Pré-dipping

21

$26 \%$

3- Pós-dipping

18

$23 \%$

4- Limpeza e desinfecção dos utensílios

21

$26 \%$

5- Não faz procedimento, pois é manual

7

$9 \%$

\section{Ações desenvolvi. p/ conserv. do meio ambiente}

1- Destinação correta dos dejetos dos animais

9

$11 \%$

2- Descarte de embalagem em local apropriado

3- Ações relacionadas à conservação de solo

4- Ações de conservação das fontes de água

5- Não desenvolve prática de conservação

0

$0 \%$

$\mathrm{Na}$ gestão de qualidade e processos de higiene, menos de $30 \%$ dos entrevistados fazem algum tipo de procedimento de higiene, e apenas $16 \%$ 
fazem limpeza e desinfecção. Portanto, percebe-se a falta de auto-estima, desmotivação em relação ao trabalho por não manter o ambiente (local de trabalho) limpo. Conforme as necessidades os produtores estão começando a investir em ordenhas, portanto ainda existem alguns que tiram leite de forma manual, e por esse motivo acreditam não ser necessário ter limpeza, mas é uma pequena parte que tem essa visão, outros já estão buscando se adaptar as demandas.

Existem várias ações para a proteção e conservação do meio ambiente, $36 \%$ faz o descarte de embalagens em local apropriado e a mesma quantidade faz a conservação de fontes de água. As fazendas na maioria têm um local apropriado para fazer o descarte das embalagens, evitando assim que os animais venham a comer embalagens e lixos espalhados na propriedade. A preocupação com o meio ambiente está cada vez mais ganhando força, portanto as exigências por conservação de reservas, fontes de águas (nascentes) está mais rigorosa e quem não cumpre a lei está sujeito a sanções do estado.

\section{7-Conclusão}

Durante o estudo e análise dos dados obtidos constatou-se que são poucos os produtores que utilizam as ferramentas de gestão disponibilizadas e não devidamente, ou seja, da maneira mais propícia para chegar aos objetivos. Deixando a desejar em sua gestão, pois dessa forma eles não estão cientes da realidade em que se encontra seu negócio, podendo tomar decisões equivocadas as quais podem levá-los a perdas.

Portanto diante desses resultados, conclui-se que é baixa a utilização das ferramentas de gestão pelos pequenos produtores de leite do município de Douradoquara MG em 2012. 


\section{REFERÊNCIAS}

BATALHA, M.O. SOUZA, F.H.M. Gestão Integrada da Agricultura Familiar. São Carlos. UdFSCar, 2005.

CAMPOS, K.C.; PIACENTI, C.A. Agronegócio do Leite: cenário atual e perspectivas. In: SOBER, XLV, 2007, Londrina. Anais... Londrina: SOBER, 2007. 19p. Disponível em:

<http://www.sober.org.br> Acesso em: 10 out 2012.

CHIAVENATO, I. Gestão de Pessoas e o novo papel dos recursos humanos nas organizações.

$2^{\circ}$ Ed. Rio de Janeiro: Elsevier, 2004. 529p.

CHIAVEnATO, I.; SAPIRO, A. Planejamento estratégico: Fundamentos e Aplicações. $11^{\circ}$ Reimpressão. Rio de Janeiro: Elsevier, 2003. 415p.

COLBEK, A.P. Uso de uma ferramenta de Gestão Rural na Agricultura Familiar: Um estudo de caso no município de Sede Nova R/S. Três Passos, 2011.

CORREA, E.L. Análise das Ferramentas de Gestão utilizadas pelos maiores produtores de leite de um laticínio na região de Monte Carmelo - MG. 2010, 56p. Graduação em Administração, Faculdade de Ciências Humanas e Sociais, Fundação Carmelitana Mario Palmério, Monte Carmelo, 2010.

CREPALDI, S.A. Contabilidade Rural: uma abordagem decisorial. São Paulo: Atlas. 3. Ed. 2005.

FONTANÉTTI, A.; SANTOS, I.C. Manejo da fertilidade do agroecossistema e a sustentabilidade da agricultura familiar. Belo Horizonte: Informe Agropecuário. v.31 - n.254, 2010.

FONSECA, C.H. Padrões de identidade e qualidade para leites fluidos tipos A, B e leite pasteurizado. Belo Horizonte: Informe Agropecuário, v. 32 - n.262, 2011.

GOMES, S.T. Benchmark da Produção de Leite em MG. Universidade Federal de Viçosa. Corpo Docente. Departamento de Economia Rural. 2005. Disponível em: <http://www.ufv.br>. Acesso em: 10 out. 2012.

GOMES, S.T. Leite era o patinho feio do agronegócio. Universidade Federal de Viçosa. Corpo Docente. Departamento de Economia Rural. Minas Gerais: 2006.a. Disponível em: <http://www.ufv.br>. Acesso em: 10 out. 2012.

GONCALVES, A.C.; COSTA, P.J.A. A influência da pecuária leiteira no meio ambiente.

MILKPOINT. Piracicaba: 2002. Disponível em: <http://www.milkpoint.com.br>. Acesso em: 10 out. 2012.

GONÇALVES, E. Gerenciamento de Propriedades Leiteiras: Gestão e Qualidade. SEBRAE-RJ / SENAR-RIO / FAERJ. Rio de Janeiro: 2007. 32p. Disponível em:

<http://www.biblioteca.sebrae.com.br> Acesso em: 10 out. de 2012.

IBGE- Instituto Brasileiro de Geografia e Estatística. Disponivel em: <http://www.ibge.gov.br> Acesso em: 27 out 2012.

LIMA, A.B. Leite e derivados: tecnologias, padrões de identidade e qualidade. Belo Horizonte: Informe Agropecuário, v.32 - n.262, 2011. 
LOPES, M.A; RIBEIRO, L.A.L; CARVALHO, F.M; PEREIRA, R.R; SANTOS, I.C; SARAIVA, F.H. Controle gerencial e estudo da rentabilidade de sistemas de produção de leite na região de Lavras(MG). Ciênc. Agrotec., Lavras: v.28 - n.4, 2004.

MAXIMIANO, A.C.A. Teoria Geral da Administração: da escola cientifica à competitividade na economia globalizada. $2^{\circ}$ Ed. São Paulo: Atlas, 2000. 530p.

MENDONÇA, F.M; SANTOS, I.C. Importância do plano de negócio para a agricultura familiar. Belo Horizonte: Informe Agropecuário, v.31 - n.254, 2010.

NAPOLEÃO, B.A. Tecnologias para a agricultura familiar: produção vegetal. Belo Horizonte:

Informe Agropecuário, v.31 - n.254, 2010.

OLIVEIRA, F.N; PIRES, J.A.A; LEITE, C.M.O. Características da produção de leite e do rebanho leiteiro do estado de Minas Gerais. Belo Horizonte: Informe Agropecuário, v.31 - n.258, 2010.

PINTO, C.L.O et al. Considerações técnicas e socioeconômicas sobre produção e qualidade de leite. Belo Horizonte: Informe Agropecuário, v.32 - n.262, 2011.

RIBEIRO, M. F. Resultados que alimentam o mundo. Revista da política agrícola. Ministério da Agricultura, Pecuária e Abastecimento. N 4, Out. /Nov. /Dez. 2011.

RIBEIRO, L.M; OLIVEIRA, M.R; FERREIRA, R.G. Saber: Administrando uma empresa rural familiar. Belo Horizonte: Sebrae-MG, 2000.

ROSA, C.A. Como elaborar um plano de negócio. Brasília: SEBRAE, 2009. 120p.

RUAS, J.R.M. et al. Produção de leite em ambiente de agricultura familiar: contribuição da pesquisa para sua sustentabilidade. Belo Horizonte: Informe Agropecuário. v.1 - n.256, 2010.

SANTOS, G.J; MARION, J.C; CEGASTE, S. Administração de Custos na Agropecuária. $3^{\circ}$ Ed. São Paulo: Atlas, 2008.

SANTOS, G.J; MARION, J.C; CEGASTE, S. Administração de Custos na Agropecuária. 4. Ed. São Paulo: Atlas, 2009. 8p.

SILVA, A.F. SANCHES, W. Boas práticas agropecuárias em ordenha mecânica na região de São Jose do rio Preto / SP. São José do Rio Preto: FATEC, 2010.

SILVEIRA, V.C.P; PEDRAZZI, P.R. As transformações na Cadeia Produtiva do Leite:

Impactos no Rio Grande do Sul e em Santa Maria. Universidade Federal de Santa Maria. 2002.

ZUIN, L.F.S; RAMOS, T.Q. Agronegócio: Gestão e Inovação. São Paulo: Saraiva, 2006. 